\title{
Agustín de Iturbide: entre la memoria y el olvido
}

Verónica Zárate Toscano INSTITUTO MORA

El silencio, el grande imperio del silencio es mucho más alto que las estrellas y más profundo que el reino de la muerte.

Tomas Carlyle

\section{INTRODUCCIÓN}

$\mathrm{E}$ 125 de abril de 1992, en la catedral de la ciudad de México se Mllevó a cabo un antiguo rito civico-religioso: unos cuantos simpatizantes colocaron un retrato al óleo de Agustín de Iturbide sobre la urna que guarda sus restos en la capilla de San Felipe de Jesús. César Jurado Lima pintó el lienzo y fue donado por José Antonio Guerrero, coordinador de un "grupo de ciudadanos dedicados a promover el ideario de Iturbide". El sacristán mayor de catedral, Luis Ávila Blancas, exaltó las virtudes del que calificó "el verdadero consumador de la independencia nacional" y asimismo recalcó que "la historia deformada de nuestro país ha satanizado a Agustín de Iturbide". ${ }^{1}$

En las postrimerías del siglo $\mathrm{xx}$, cuando el discurso de la modernidad se repite con frecuencia y han transcurrido más de 170 años desde que México se convirtió en un país independiente, aún existen personas y asociaciones que reclaman para Iturbide un lugar junto a los héroes nacionales. Tomás Carlyle - estudioso del culto a los héroes-señaló que a mediados

\footnotetext{
1 Excélsior, 26 abril 1992, pp. 4 y 6.
} 


\section{SECUENCIG}

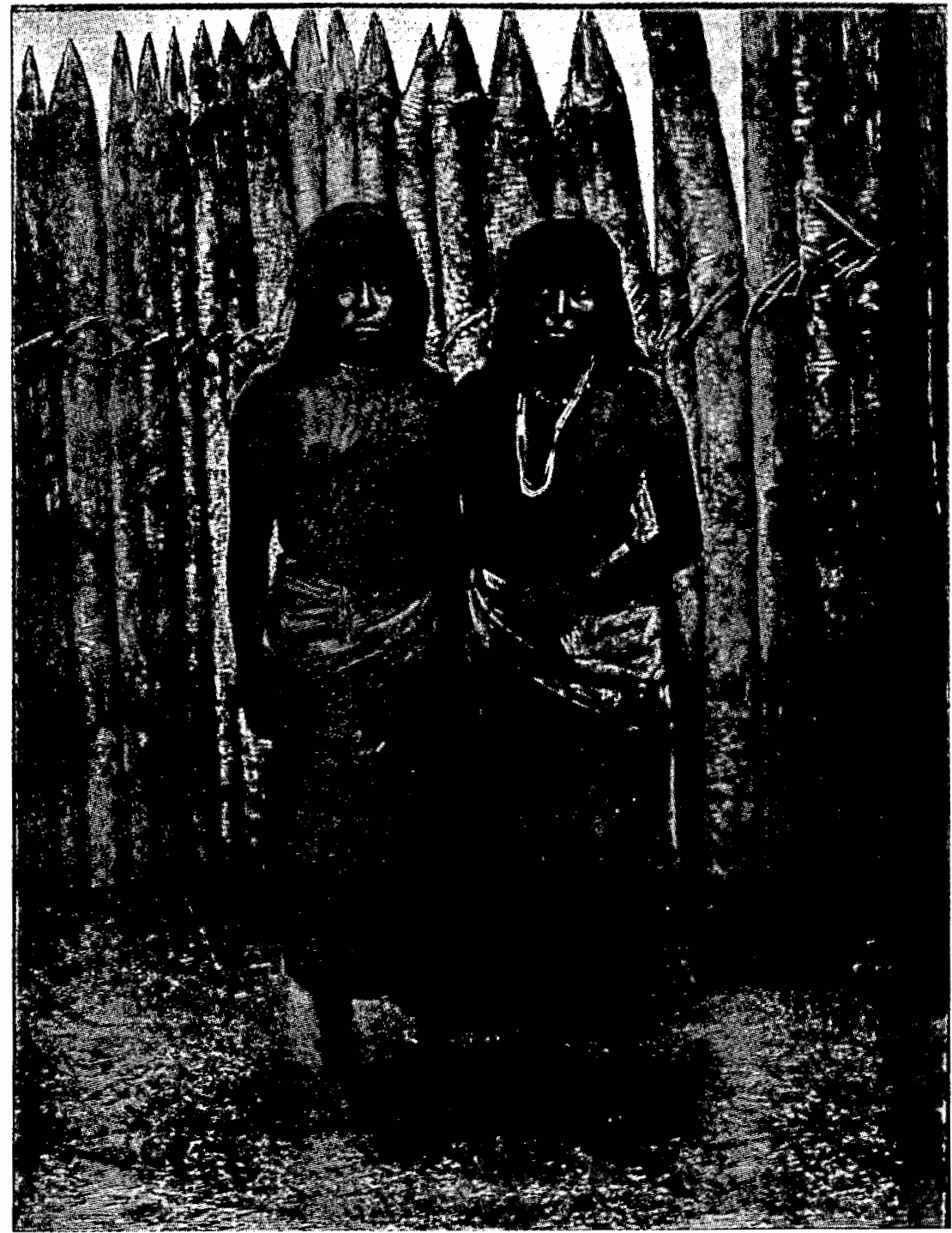


del siglo pasado las sociedades tenían una especial predilección por cultivar su memoria, al grado de formar una "heroearquía". Pero igualmente observó que no sólo era necesario el "héroe, sino un mundo dispuesto a recibirlo como corresponde". ${ }^{2}$

En este ensayo me propongo analizar cómo se intentó, desde el siglo pasado, fomentar el culto que reconociera a Iturbide como uno de los forjadores de la nación tratando de inventar una tradición.

Las tradiciones inventadas estable. cen o simbolizan la cohesión social de los grupos y comunidades; legitiman instituciones y relaciones de autoridad, $o$ inculcan creencias, sistemas de valores y comportamientos. El éxito de las invenciones está en función directa con la difusión que se les otorgue y con la predisposición de los distintos sectores de la sociedad para aceptarlas. En esto juegan un papel principal el desarrollo de la educación, la invención de ceremonias públicas y la producción de monumentos públicos. ${ }^{3}$

\section{LA MUERTE DE ITURBIDE}

Desterrado en 1823, Agustín de Iturbide viajó a Europa y se estableció tem-

2 Carlyle, Héroes, 1976, p. 175.

3 Hobsbawm, Tradition, 1983 , p. 271 . A la luz de estos elementos, para el análisis que me propongo me apoyaré en fuentes de índole muy diversa, como las historias clásicas, las crónicas de testigos participantes activos o pasivos de la muerte de Iturbide así como de la exhumación, traslado y depósito de sus restos, e igualmente de las opiniones expresadas en la prensa, folletos y pasquines, en el momento de su muerte y resurrección. poralmente en Liorna, Italia. A principios de 1824 se trasladó a Londres y para mediados de mayo se embarcó en el bergantín Spring.

El 12 de julio, a bordo del barco aunque ya muy cerca de la costa mexicana, Iturbide escribió su testamento. ${ }^{4}$ En él evocó su religión (católica), el destino de su cuerpo ("quiero que sea sepultado sin pompa alguna, aunque sí mando se hagan sufragios para mi eterno descanso"), su estado civil (casado con ocho hijos vivos y uno más en el vien. tre de su esposa), sus deudas (contraidas en México e Inglaterra), sus posesiones (una hacienda en Apeo, jurisdicción de Maravatío, y otra arrendada en Chalco), sus acreedores (el gobierno mexicano), sus disposiciones piadosas (sostenimiento de dos huérfanas y otras no especificadas), sus herederos (su padre y todos sus hijos), el nombramiento de tutor para los hijos menores (su esposa Ana María Huarte) y de sus albaceas (Juan Gómez Nava. rrete, Nicolás Carrillo y José Antonio López) y finalmente la revocación de testamentos anteriores (que aparentemente no existen). ${ }^{5}$

Después de la larga travesía, pisó tierra en Soto la Marina, Tamaulipas, el 15 de julio de 1824. El general Felipe de la Garza -a quien el consumador había salvado la vida en alguna ocasión- arrestó a Iturbide y le informó que, por decreto de 28 de abril del propio año, se le había declarado fuera de la ley y en el momento que pisara

${ }^{4}$ Los militares tenían facultad para escribir su última voluntad en papel simple y en cualquier lugar.

5 Archivo de Notarías de la Ciudad de México (ANCM), Francisco Calapiz, 9 febrero 1832. 
tierra mexicana se le condenaría a muerte. Dicha disposición fue ratificada por el Congreso de Tamaulipas y a las seis de la tarde del día 19 de ese mismo mes, Agustín de Iturbide, a sus cuarenta años de edad, fue pasado por las armas en la pequeña Villa de Padilla. ${ }^{6}$

De la Garza informó al ministro de Guerra que, cuando llegó el momento, formó a la tropa y al sacar a Iturbide éste dijo:

A ver, muchachos, daré al mundo la última vista." Volteó a todos lados, preguntó dónde era el suplicio y, satisfecho, él mismo se vendó los ojos, pidió un vaso de agua que probó solamente [...] Su marcha de más de 80 pasos y su voz fueron con la mayor entereza. Llegando al suplicio se dirigió al pueblo: "Mexica. nos: en el acto mismo de mi muerte os recomiendo el amor a la patria, y obser. vancia de nuestra santa religión; ella es quien os ha de conducir a la gloria. Muero por haber venido a ayudaros, y muero gustoso porque muero entre vosotros. Muero con honor; no como traidor; no quedará a mis hijos y su posteridad esta mancha; no soy traidor; no. Guardad subordinación y prestad obediencia a vuestros jefes, que haciendo lo que ellos os mandan, cumpliréis con Dios." Besó el Santo Cristo y murió al rumor de la descarga. ${ }^{7}$

El temor de Iturbide de ser considerado un traidor a la patria se volvería

6 Para una mayor información véanse Beneski, Narración, 1977; Malo, Apuntes, 1869; Catástrofe, 1826, y Robertson, Iturbide, 1952, principalmente.

7 De la Garza al ministro de Guerra, en Zorrilla, Diaz, 1969, pp. 143-144. Las cursivas son mías. una realidad repetida hasta el cansancio en la historia oficial de México. Los intentos por redimirlo siempre lo resaltarían como el libertador y consumador de la independencia, callando la ignominia de haberse ceñido la coro. na de emperador.

Correspondió al propio De la Gar$\mathrm{za}$, su ejecutor, financiar el entierro. El 13 de agosto de 1824 informó al ministro de Guerra, Manuel Mier y Terán, que tras el fusilamiento, el cuerpo, vestido con el hábito franciscano, fue velado en la capilla que servía de sala de sesiones del Congreso.

La mañana del 20 se convidó para la misa y entierro, al que asistieron los individuos del Congreso, lo más del pueblo y la tropa. Concluida la misa y vigi. lia, se acompañó al cuerpo haciéndole cuatro posas en la plaza a la iglesia vieja sin tejado, donde se le dio sepultura como a las ocho del día. ${ }^{8}$

La misa de réquiem fue oficiada por el padre José Antonio Gutiérrez de Lara quien había fungido como confesor del condenado. Cabe señalar que el sacerdote era presidente en turno del Congreso local que confirmó la sentencia de muerte de Iturbide, aunque algunas fuentes indican que rehusó participar en la votación decisiva.

Es digno de resaltarse que las autoridades locales en pleno asistieron a la ceremonia religiosa, sancionando con su presencia la importancia del evento. Después de haberlo ejecutado, le

8 "Relación circunstanciada que da el general ciudadano Felipe de la Garza del desembarco y muerte de don Agustín de Iturbide al ministro de Guerra", en Gutiérrez, Papeles, 1977, p. 360. 
rendían toda clase de honores. Y más adelante, el cuerpo legislativo local sintió la necesidad de reafirmar su decisión de fusilarlo a la vista de los atropellos cometidos por el déspota. ${ }^{9}$

Iturbide había justificado su regreso diciendo que venía a ponerse al servicio de la patria para defenderla de las amenazas de las potencias europeas. Este argumento sirvió como base para que en boca y pluma de sus partidarios apareciera la acusación de que se había apresurado la decisión de fusilarlo e incluso que había sido un acto ilegal..$^{10}$

\section{ITURBIDE ANTE LA TRADICIÓN}

El momento en que Iturbide traspasó el umbral de la muerte, parecería el adecuado para ingresar a la historia. La opinión pública jugó un papel importante en el intento de justificar su muerte, de criticar sus errores y de crear la leyenda del "Héroe de Iguala".

La noticia de su fusilamiento inicialmente se hizo pública en el periódico $E l$ Sol, que la destacó bajo el llamativo encabezado de "Ejecución de Iturbide". ${ }^{11}$ Esta información llegó a los lectores de la ciudad de México el mismo día que fue dada a conocer por los ministros de Guerra (Mier y Terán) y Relaciones (Lucas A lamán) , ${ }^{12}$ en la sala de

9 Zorrilla, Díaz, 1969, pp. 8890, reproduce el manifiesto del Congreso publicado el 6 de agosto de 1824 en el Termómetro Político del Estado Ltbre de Tamaultpas.

10 Véase por ejemplo la opinión de José María Bocanegra, Memorias, 1985, vol I, pp. 316-317.

11 El Sol, núm. 408 , p. 165 , lunes 26 julio 1824.

12 Cabe destacar que, más adelante, las opi- sesiones del Congreso General a donde, según refiere Carlos María de Bustamante, había llegado cerca de las once y media de la mañana. ${ }^{13}$ La nota periodística es un tanto ambigua porque en ella se combinan dos informa. ciones: primero se alientan las esperanzas de los iturbidistas y a la vez se avivan los temores de sus enemigos con la noticia de que se encuentra rumbo a México. Sin embargo, letras después, se afirma que ha sido fusilado, con lo que se desencanta a sus seguidores y se alivia a sus adversarios.

El público pudo enterarse - a través de las actas de las sesiones del Congreso que ocupaban un espacio considerable en la prensa del momento-de la posición adoptada en dicho órgano ante tamaño acontecimiento al manifestar su satisfacción por la conducta del cuerpo legislativo de Tamaulipas. ${ }^{14}$ Además, en los días subsecuentes y a través de los periódicos, se dieron a conocer cuantos documentos se conocían relacionados con el suceso así como la discusión en torno al destino que se daría a la familia de Iturbide, que había desembarcado en suelo mexicano. ${ }^{15}$

Si al momento de abdicar Iturbide,

niones de ambos tendrían un gran peso en el destino histórico de Iturbide.

13 Bustamante, Diario, 1981, vol. II, p. 102.

14 El Águila Mexicana, núm. 104, martes 27 julio 1824 .

15 El Águila Mextcana, núm. 106, y El Sol, núm. 411, jueves 29 julio 1824; Bustamante, Diario, 1981, vol. II, p. 103. Se proponía enviarlos a Colombia pero a falta de un barco que llevara ese destino, se embarcaron a Nueva Orleans, donde nació el hijo póstumo. Posteriormente, Ana María Huarte, su viuda, se trasladó a Filadelfia, donde residió hasta su muerte en 1861 . Heliodoro Valle, Iturbide, 1944, p. 184. 
se había desbordado la opinión pública con la aparición de múltiples folletos, una vez muerto el personaje no sería menos impactante e irónica la nueva producción. ${ }^{16}$ Todos estos escritos mantenían a Iturbide vivo sin importar la tendencia que siguieran ni el tratamiento que le dieran.

Además, el nombre del consumador estaba en boca de la gente de cualquier facción y a la menor provocación era sacado a relucir para atacar o defender sus acciones. Alamán por ejemplo reflexionó ante el Congreso que, con la muerte de Iturbide, habían terminado las posibilidades de acción del grupo de iturbidistas y por tanto ya no era necesario seguir expatriándolos ni persiguiéndolos. Esta propuesta de amnistía no fue admitida a discusión ya que los ánimos estaban demasiadó encendidos para perdonar a Iturbide y a los de su facción. ${ }^{17}$

Por su parte, Lorenzo de Zavala escribiría más adelante que había sido testigo de la exaltación manifestada en la ciudad de México por los "indignos mexicanos que aborrecían en Iturbide al libertador de su patria". No está por

16 De la primera etapa vale la pena mencionar los titulados Manda nuestro emperador que ninguno le obedezca; Muerte y entierro de Agustín Primero; y Segunda parte o conclusión del testamento de Iturbide. En la segunda destacan los del Pensador Mexicano: Pésame del Pensador por la muerte de Iturbide, a sus apasionados; En donde murió Iturbide, viven en paz los traidores, así como los del Payo del Rosario: A la grata memorta de Iturbide, y Nos va dando cierto olor a segundo emperador; o sea la Logia de los gatos. Éstos y otros han sido registrados en Morreno Valle, Lafragua, 1975.

17 El Águila Mexicana, núm. 113, martes 5 agosto 1824 . demás recordar que dicho autor había sido inicialmente colaborador de Iturbide pero que, poco después, se enemistó con él por sus tendencias absolutistas e incluso formó parte de la comisión del Congreso que dispuso el destierro del emperador. Y sin embargo, manifestando una opinión que podía parecer contradictoria, plasmó su consternación por la muerte del personaje. Su apreciación nos transmite la existencia de emociones encontradas que condenaban la posición política de Iturbide pero a la vez lamentaban su muerte.

Otro de los historiadores-participantes de esta época, Bustamante, con esa rabiosa crueldad y pasión que denota en su Diario, comentó en 1824 que los iturbidistas se habían "atrincherado" no creyendo que su amo había muerto. Agregó que era "menester dejarlos en su error y obstinación como se tolera a locos indomables". ${ }^{18}$

Una última opinión digna de tomarse en cuenta es la expresada en 1827 por el editor mexicano de las Memorias de Iturbide, quien consideraba que su muerte había tranquilizado a la patria pero esa misma paz se habría logrado haciéndole reembarcar, "pues creo que sabiendo la ley que lo proscribía y notando la decisión de la patria por la forma democrática, no se hubiera aventurado a un segundo golpe. ${ }^{19}$ Esta es la voz, tal vez un tanto tímida,

18 Bustamante, Diario, 1981, vol. II, p. 103. Aparentemente esa incredulidad tardaría mucho en desaparecer y aun al momento de informarse que entraría a la ciudad de México muchos años después, no faltó quien creyera que lo haria por su propio pie y no dentro de una urna.

19 Iturbide, Breve, 1827. 


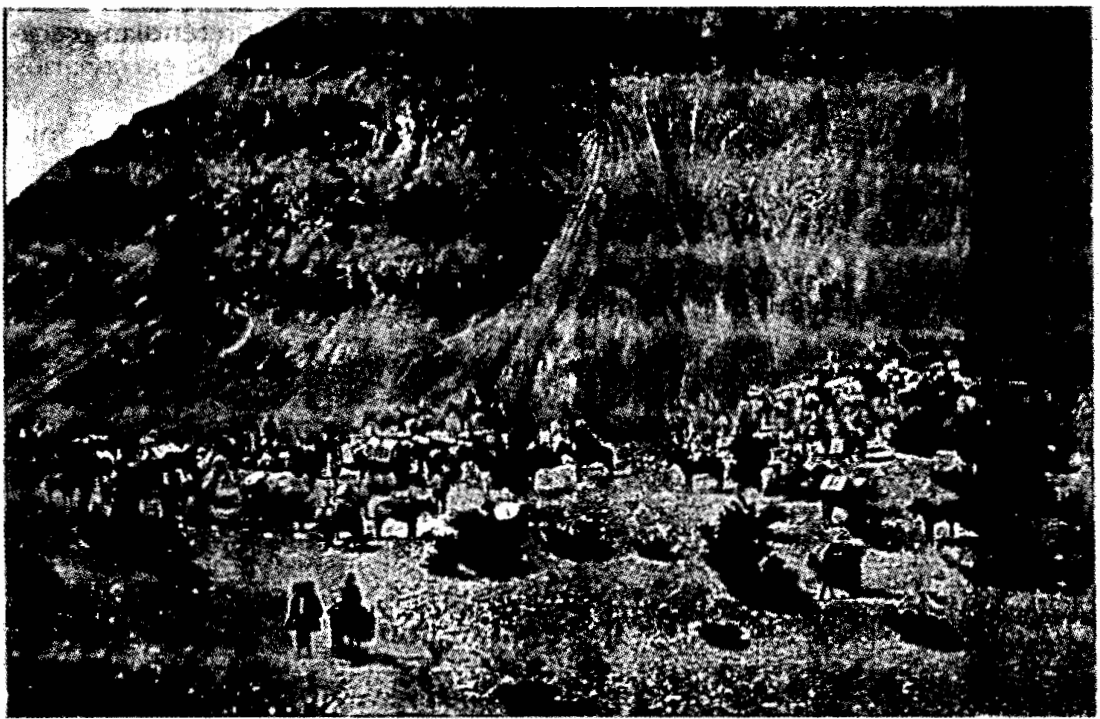

que confiaba en la buena fe de Iturbide y que lo hacía merecedor del perdón.

\section{PRIMEROS RECONOCIMIENTOS}

Los iturbidistas no quitaron el dedo del renglón y paulatinamente fueron obteniendo muestras de reconocimiento para su líder espiritual. Aunque se consideren logros aislados, parecen encaminados al reconocimiento de los triunfos de ese grupo y, puestos en perspectiva, apuntan precisamente hacia la formación de una tradición inventada.

Así pues, en septiembre de 1832 el gobierno-ocupado interinamente por Melchor Múzquiz- determinó que la viuda y familiares de Iturbide recibieran una pensión vitalicia similar a la otorgada a la viuda de Juan O'Donojú, de 12000 pesos anuales. ${ }^{20}$ Al año siguiente, el 3 de noviembre, el general Antonio López de Santa Anna decretó que las cenizas de Iturbide se trasladaran a México para ocupar su lugar en el sitio destinado a los héroes de la independencia. ${ }^{21}$

Las reglas para establecer la tradición parecían irse acomodando paula-

20 Robertson, Iturbide, 1952, p. 304.

21 Alamán, Historia, 1985, vol. v, p. 802. El decreto enfatizaba que "la nación mexicana, tan justa cuando castiga la usurpación de sus derechos como cuando recompensa las grandes acciones de sus hijos, lo reconocía como uno de los autores de su independencia, por haberla proclamado en Iguala y conquistádola con su prudencia y valor". 
tinamente. Por una iniciativa del di. putado Felipe Neri del Barrio, se decretó el 20 de mayo de 1835 que se inscribiera con letras de oro el nombre de Agustín de Iturbide en el salón de sesiones del Congreso General. ${ }^{22}$ Paradójicamente, el hecho sirvió para conmemorar el decimoprimer aniversario de su fusilamiento. Asimismo el gobierno se comprometió a pagar el millón de pesos que habían sido ofrecidos a Iturbide en 1822 por haber consumado la independencia "cuando las condiciones del tesoro nacional lo permitieran". 23

En marzo de 1832, Mier y Terán en. cargó a su ayudante José María Díaz Noriega que se dirigiera a Padilla para averiguar la supuesta exhumación de los restos de Iturbide. ${ }^{24}$ Un sargento que había participado en dicha acción, le informó a Díaz Noriega que efectivamente se había intentado sacar los restos pero, al hacerlo, habían surgido todo tipo de temores. En vista de no tener preparado lo necesario para "su traslación oculta", se le ordenó cubrir la fosa pero antes de hacerlo, "deseoso de conservar separados aquellos respetables restos", usó para ello el marco de una puerta de madera de sabino que estaba construyendo. 25

Los coroneles José María Barberi y José Martínez Chavero habían dado la orden y por ese motivo se les enjuició. Desafortunadamente, hasta ahora no se ha encontrado información suficiente sobre las intenciones de los mi-

22 Ibld.

23 Robertson, Iturbide, 1952 , p. 304.

24 Díaz, Funestos, 1860.

25 Ibid., p. 35. litares para saber si pretendían rescatar los restos del olvido o extraviarlos para siempre.

En julio de ese mismo año, el propio Mier y Terán visitó Padilla y se dirigió al sepulcro de Iturbide, ubicado en el cementerio de la iglesia. La fosa se localizaba cerca de la puerta principal y estaba cubierta de plúmbago y sin ninguna señal fúnebre. Tras conocer el informe sobre la identificación de los restos, dijo a su ayudante que su amistad exigía que, haciendo los gastos de su cuenta, "legalmente" se hiciera la exhumación y se depositaran "esos manes en lugar que debe" ${ }^{26}$

Al día siguiente, Mier y Terán fue encontrado con una espada clavada por su propia mano. ${ }^{27}$ No es fácil explicar por qué la última voluntad del antiguo insurgente fue rescatar los restos del consumador de la independencia con quien tanto había disentido. Mucho menos se ha encontrado una respuesta convincente de por qué escogió la población de Padilla para quitarse la vida.

Y como otra paradoja de la historia, Díaz Noriega decidió sepultar a su comandante en el mismo sitio donde descansaba el olvidado libertador. Al cavar la fosa, encontró la puerta que identificaba los restos de Iturbide y los exhumó para que fueran examinados por los cirujanos, aunque los presentó

algo incompletos, porque al sacarlos del sepulcro algunos de los espectadores los tomaron, besaron y ocultaron, en términos que me fue indispensable usar de la fuerza para su restitución. ${ }^{28}$

26 Ibid., pp. 35-36.

27 Payno, Bosquejo, 1843, p. 34.

28 Díaz, Funestos, 1860, p. 37. 


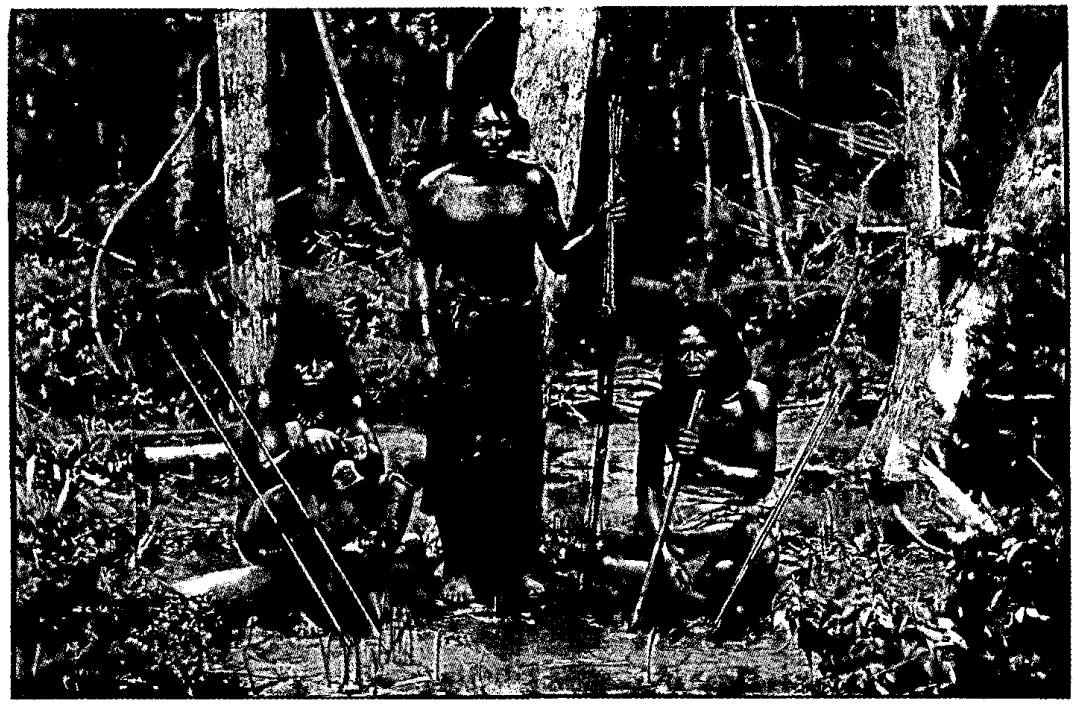

Resulta emotivo el hecho de que los restos de Iturbide, con el paso del tiempo, se hubieran convertido en verdaderas reliquias dignas de veneración profunda. ${ }^{29}$ Díaz Noriega aprovechó este valor simbólico para conmover los sentimientos de algunos influyentes que pudieran auxiliar en el rescate del héroe de Iguala. Ofreció la bala que fue extraída del

29 Según refiere el sobrino de Iturbide, José Ramón Malo, en sus Apuntes, 1869 , p. 159, al momento de preparársele para enterrarlo tras el fusilamiento, se permitió a los soldados tomar algunas prendas del difunto. Cuando vio a un oficial con las botas de su tío, le reconvino por aquel desacato a lo que aquél contestó que "las había tomado por reliquia". Más que objeto de veneración, era la oportunidad de obtener un buen calzado.
cráneodeIturbidealdiputadoJoséRamón Pacheco y regaló un hueso de la manoderechaalgeneralManuelReyes Veramendi.

Comprendiendo, pues, que la situación y el momento no eran los más favorables para cumplir la última voluntad de Mier y Terán, Díaz Noriega se limitó a sepultar a su comandante y a volver a poner los restos de Iturbide en su lugar. Enemigos en vida, habrían de quedar unidos en la muerte. Posteriormente se trasladó a la ciudad de México y comenzó a mover los hilos políticos necesarios para el rescate. Logró acercarse a Santa Anna y le descubrió "su empeño por perpetuar la memoria del libertador y la traslación de sus venerables restos". La respuesta del general fue la expedi- 
ción del decreto de 1833 sobre la traslación de las cenizas.

\section{LOS HÉROES DE LA INDEPENDENCIA}

El año de 1838 parecía el apropiado para el rescate de Iturbide, ya que los conservadores, por segunda ocasión, habían colocado en la silla presidencial a Anastasio Bustamante. Éste era un federalista moderado, antiguo militar realista, perseguidor en su momento de Morelos y Mina, que se había adherido al plan de Iguala. Cuando entró en Guanajuato en marzo de 1821,

para hacer desaparecer los recuerdos odiosos de la insurrección, hizo quitar de la alhóndiga de Granaditas, las cabezas de Hidalgo y sus compañeros que estaban colocadas en jaulas de fierro en los cuatro ángulos de aquel edificio de tan funesta memoria y las mandó enterrar en la iglesia de San Sebastián. ${ }^{30}$

En este significativo hecho se descubre la intención de mostrar respeto por los restos de los iniciadores de un levantamiento que, a diez años, mostraba características distintas a las que originalmente había tenido. Aunque parezca paradójico, puede verse como un acto generador de una nueva simbología política.

Una vez consumada la independencia en 1821, surgió la propuesta de rendir honores a los caudillos insurgentes pero el consumador Iturbide se negó. Sin embargo, una vez que abdicó, se trasladaron los restos de los héroes a la ciudad de México para ser

30 Alamán, Historia, 1985, vol. v, p. 153. depositados en el Altar de los Reyes y en la capilla de San José de la catedral metropolitana.31 Y es que, como bien ha observado recientemente Timothy Anna, ese manojo de caudillos estaban "convenientemente muertos y por tan. to eran inocentes de pecados políti$\cos " .32$

Por su parte, cabe resaltar que los nombres de Iturbide y Vicente Guerrero, unidos en vida en el simbólico "Abrazo de Acatempan", también se vincularían en la muerte. Poco después del fusilamiento del segundo en febrero de 1831, se publicó en la ciudad de México un verso titulado "A Iturbide y Guerrero. Recordamos sus nombres y cadáveres deseamos." A pesar de los honores que se le habían rendido en el estado que ahora lleva su nombre, la opinión pública no consideró que fuera homenaje suficiente. Así que cuando se depositaron en la catedral los restos de Iturbide, el editorialista del periódico El Cosmopolita se preguntaba por qué no se habían conducido a la capital los restos del héroe del sur, y condenaba que las autoridades fomentaran distinciones antisociales. ${ }^{33}$ Cinco años más tarde, Guerrero ingresó a la catedral.

En 1925, y para terminar aparentemente con el peregrinar de los héroes, los restos de Miguel Hidalgo, Mariano Matamoros, Xavier Mina, Nicolás Bravo y Vicente Guerrero fueron traslada. dos a la columna de la Independencia,

31 Miquel, Diccionario, 1980, p. 97; Argandar, Elogio, 1823.

32 Anna, Imperio, 1991, p. 241. 1838.

33 El Cosmopolita, núm. 92, 24 octubre 
erigida en el Paseo de la Reforma e inaugurada en 1910 con motivo de las fiestas del Centenario. ${ }^{34}$ Cuando un diplomático extranjero preguntó al presidente Plutarco Elías Calles por qué no se incluían los restos de Iturbide, contestó "dejémoslos estar entre aquellos a los que pertenecía", aludiendo a que sólo los de Agustín I quedaron en la catedral de México. ${ }^{35}$

Todos ellos fueron símbolos civiles pero con grandes diferencias: iniciadores, consumadores y continuadores merecían distintos niveles de reconocimiento por su labor.

\section{EL TRASLADO}

Con el título de un folleto que salió a la circulación en el segundo semestre de 1838: Del grande Iturbide se puede decir que vino a reinar después de morir, ${ }^{36}$ se puede resumir una idea que aparentemente flotaba en el ambiente en esos días.

La iniciativa de Díaz Noriega se san. cionó finalmente con un decreto del Congreso fechado el 6 de agosto de

${ }^{34}$ Recientemente se han destinado recursos para comprobar si, como se cree, los restos de José Maria Morelos fueron llevados a París por su hijo Juan Nepomuceno Almonte. Excélsior, 5 noviembre 1991.

35 Gutiérrez, Papeles, 1977, p. 7, y Robertson, Iturbide, 1952, p. 305. La vinculación entre el ex emperador y la Iglesia se había venido manejando insistentemente a todo lo largo del siglo xxx pero este comentario adquiere importancia por haberse expresado en una época en que las relaciones entre la Iglesia y el Estado estaban particularmente tensas.

36 Incluido por Bustamante en su Diario, correspondiente a octubre 1838 .
1838. ${ }^{37}$ A partir de ese momento, la última voluntad de Miery Terán se con. virtió en un proyecto del gobierno de Anastasio Bustamante.

Cabe señalar que, dentro de las tradiciones, las fechas juegan un papel por demás significativo. En el caso que nos ocupa, se buscó la coincidencia del traslado de las cenizas con la fecha de la consumación de la independencia en vez de entronizar un nuevo día y celebrarlo en lo sucesivo como "Aniversario del regreso de Iturbide" o algo por el estilo. Pero, además, el día 27 de septiembre ya había sido objeto de controversias. Iturbide lo había dejado establecido como la fecha para conmemorar la independencia porque era el día en que él había entrado a la ciudad de México a la cabeza del ejército Trigarante. Pero a la caída del emperador se le dio mayor importancia al 16 de septiembre, resaltando el mérito de los insurgentes que habían iniciado el movimiento. ${ }^{38}$ Cuando Anastasio Bustamante ocupó la vicepresidencia en 1830 rescató la celebración original, ${ }^{39}$

37 Pacheco, Descripción, 1849, p. 61. El decreto decía en su parte central: "El gobierno dispondrá que las cenizas del Héroe de Iguala don Agustín de Iturbide, sean trasladadas a la capital de la república para el día 27 de septiembre próximo, aniversario de su entrada en ella, y en el que consumó gloriosamente la independencia de la patria. También dispondrá lo conveniente para que las expresadas cenizas sean colocadas en la catedral de México, lugar destinado para los héroes".

38 Otra fecha "a conmemorar" en el calendario cívico de México que resulta un tanto extraña es el $\mathbf{2 0}$ de noviembre en que se festeja el inicio de la revolución mexicana. Sin embargo, ese día de 1910 en realidad no sucedió nada. 768 .

39 Alamán, Historia, 1985, vol. v, pp. 767 . 
y en 1838 la ratíficó al seleccionar ese día para el ingreso de Iturbide al pan. teón de los héroes.

El Congreso solicitó al propio Díaz Noriega que llevara adelante su iniciativa y, por tanto, se trasladara a Padilla a traer los restos del ex emperador. Sin embargo el general declinó tal invitación y por ello se confió la honrosa comisión al gobernador del estado de Tamaulipas, Antonio Quintero. ${ }^{40}$

El 22 de agosto, en medio de "una numerosa comitiva", se efectuó "con el mayor respeto" la exhumación de los restos, mismos que fueron examinados, autentificados e inventariados. Los que habían sobrevivido al deterio-

40 Día, Funestos, 1860, pp. $41-42$. ro del tiempo -y a los coleccionistas-, se depositaron en una urna de madera forrada de terciopelo negro, con galo. nes y franjas de oro y trasladados al interior de la iglesia donde se celebró un responso, el primero de la nueva etapa de veneración del héroe. ${ }^{41}$

Al día siguiente se inició el peregrinar que marcaba el retorno del hijo pródigo. Existen diversas relaciones de las honras que se le tributaron en su ruta a la capital de la república. ${ }^{42} \mathrm{La}$ más conocida es la de José Ramón Pa. checo, quien refiere que no hubo

41 Pacheco, Descripción, 1849, pp. 62-64. Véase además El Irts, núm. 137, 22 septiembre 1838.

42 Pacheco cita el diario que llevó el encarga. do de la conducción, Francisco Molina, en el que se detallan las manifestaciones de cada lugar.

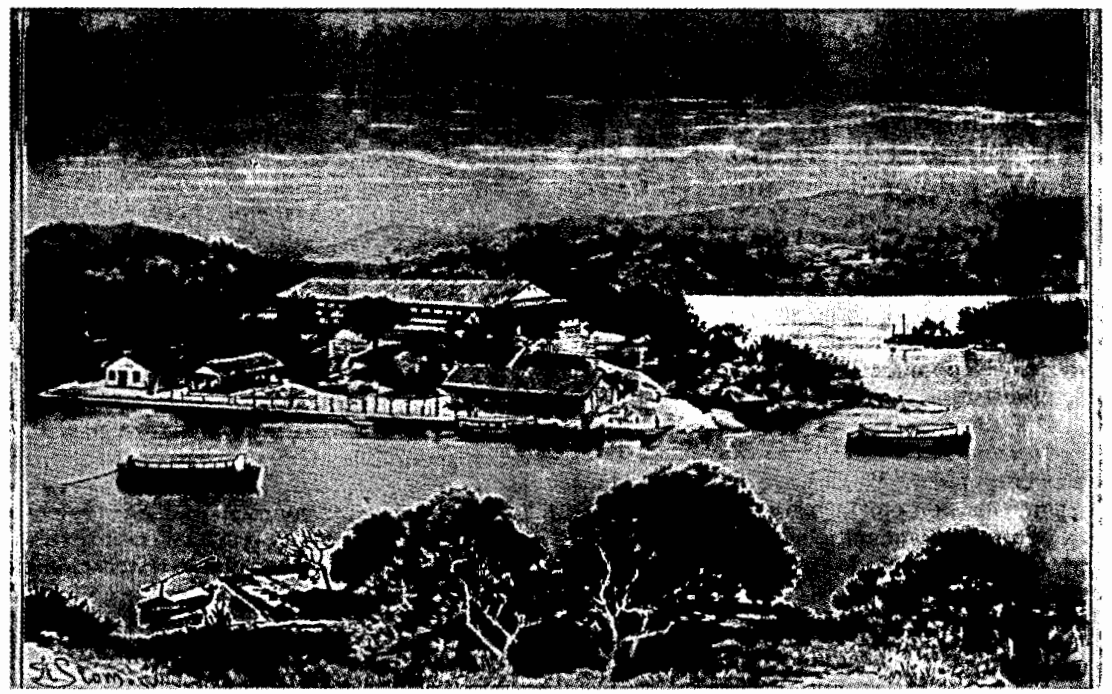


ni un instante, ni de día ni de noche, que no haya tenido delante de sí ojos vigilantes, ojos inundados de llanto, corazones traspasados de un dolor de despecho. [Tampoco hubo ningún sitio] en donde no hayan salido las poblaciones en masa a recibir las cenizas del señor Iturbide. No precedió ninguna ley, ninguna orden, ningún ceremonial ni reglamento, y las manifestaciones espontáneas han sido las mismas en todas partes sin más diferencias que la de los recursos en ca. da lugar. ${ }^{43}$

Los partidarios de Iturbide creian en la existencia de un aprecio espontáneo del pueblo hacia el libertador, sentimiento que podía ser fácilmente explotado para consolidar la tradición de venerarlo como héroe. Sin embargo, según las versiones contrarias, esta multitud únicamente había acudido a presenciar el paso del antiguo emperador movida por la curiosidad y el morbo. ${ }^{44}$ De cualquier manera, las crónicas coinciden en la presencia de un "concurso numeroso" que acompañó el tránsito y la entrada de Iturbide. Los motivos que tenían para estar ahí no se pueden documentar fácilmente pero son de naturaleza múltiple y están en espera de una explicación histórica.

\section{LA ENTR ADA DE ITURBIDE A MÉXICO}

Aunque a lo largo del recorrido no fueron necesarias leyes y reglamentos que orquestaran los homenajes, en la ciudad de México se imprimió una hoja suelta en la que el gobernador del de-

43 Pacheco, Descripción, 1849, p. 28.

4 Bustamante, "Diarion", 25 octubre 1838. partamento y los miembros del ayuntamiento apelaban al "patriotismo" de los ciudadanos para que recibieran a Iturbide. ${ }^{45}$ Una comitiva oficial se trasladó a la garita de Cuautitlán -en las orillas de la ciudad- para recibir al cortejo fúnebre. En medio de una creciente multitud, los restos se condujeron hasta la iglesia de la Colegiata, en la actual Villa de Guadalupe, donde solemnemente se instaló la "urna en una suntuosa pira colocada en el centro y cantó una vigilia que duró más de una hora". ${ }^{46}$

Posteriormente, los restos se colocaron en un "landó" abierto, el cual iba seguido por el coche del presidente Bustamante y 400 vehículos más. En medio de descargas de artillería, tañidos de campanas y el júbilo de una multitud que formaba valla, el cortejo llegó a San Francisco donde lo aguarda. ban las comunidades religiosas. Después de un "solemne responso a toda orquesta", los restos de Iturbide se depositaron en la Capilla del Noviciado. En un principio se había pensado que permanecierah en San Francisco un par de días hasta que fueran colocados en la catedral el día 27 de septiembre. Por diversas circunstancias no se pudo hacer la ceremonia en esa fecha y se movió el acto para el 27 de octubre, en que se conmemoraba la jura de la independencia.

Una comisión creada para el efecto formó el 12 de octubre de 1838 el "Reglamento para el ceremonial con que deben ser trasladados y colocados en la catedral de México los restos del hé-

45 Entrada, 1838.

46 El Iris, 26 septiembre 1938. 
roe de Iguala don Agustín de Iturbide" ${ }^{47}$ En sus quince artículos se especificaban las ceremonias a efectuar en San Francisco y catedral, ruta a seguir, cañonazos y campanadas, uniformes de los conductores, demostraciones de luto en ciudadanos y habitaciones, colocación jerárquica del cortejo, momento para dar el pésame al presidente y la publicación de una "descripción minuciosa". Asimismo, se ordenaba que en todas las ciudades donde no se hubiera hecho ninguna ceremonia, se verificaran los sufragios correspon. dientes. Confrontando lo estipulado en el reglamento con las descripciones que se han conservado, puede verse qué tanto eco encontró entre la población una iniciativa gubernamental encaminada a formar una tradición. 48

Así pues, a partir del 24 de octubre se celebraron buen número de misas en el convento de San Francisco, cuya iglesia estaba magníficamente enlutada. Sobre la negrura de los lienzos resaltaban los colores del pabellón tricolor que se hallaba suspendido de la cúpula. Esto parecía ser un recordatorio de que se rendían honores al hombre que había ideado el símbolo nacional por excelencia: la bandera.

47 Estaba integrada por el general Manuel Barrera, el coronel Felipe de Jesús Azcárate, el presbítero Pedro Fernández y el contador mayor Tranquilino de la Vega. El Cosmopolita, núm. 92, y El Iris, núm. 144, ambos del 24 de octubre de 1838.

48 Al referir estos sucesos, vienen a la memoria las ceremonias hechas en Francia para el retorno de las cenizas de Napoleón en 1840, durante el reinado de Luis Felipe y su depósito en Los Inválidos en 1861 en pleno auge del imperio de Napoleón III. Véase Tulard, "Retour", 1986.
En el centro del templo se había dispuesto un catafalco de más de 30 pies de elevación, en cuya punta truncada se colocaron los restos de Iturbide dentro de una urna de cristales y bronce dorado; 49 la pira funeraria estaba rodeada de dos hileras de humeantes velas que iluminaban el recinto y resaltaban el retrato de Agustín de Iturbide. En la base de la pirámide se colocaron algunas de sus prendas revestidas de gran simbolismo: su uniforme de general mexicano con banda, bastón, espada y sombrero, así como el manto de la Orden de Guadalupe creada por él en 1822 para constituir una aristocracia mexicana. A juzgar por la litografia de Ignacio Cumplido, que captó la suntuosidad de ese momento, el efímero monumento se asemeja a los que se hacían a la muerte de los soberanos españoles..$^{50}$ Once años de lucha por independizarse de España no habían desarraigado costumbres de tres siglos.

La mañana del 26 de octubre algunas casas amanecieron adornadas y sobre las calles recién barridas de todo el recorrido, se había tendido "la vela", tal como se hacía en la festividad de Corpus para cubrir el paso del Santísimo. Después de las misas en San Francisco, a las once de la mañana se inició la marcha en medio de cañonazos y campanadas a través de las calles de San Francisco, por Plateros, torciendo por el Portal de Mercaderes, para tomar las calles de las casas consistoriales, el Portal de las Flores, la

49 Pacheco, Descripción, 1849, p. 78.

$50 \mathrm{Fid}$., incluye una litografia alusiva de Ignacio Cumplido. 


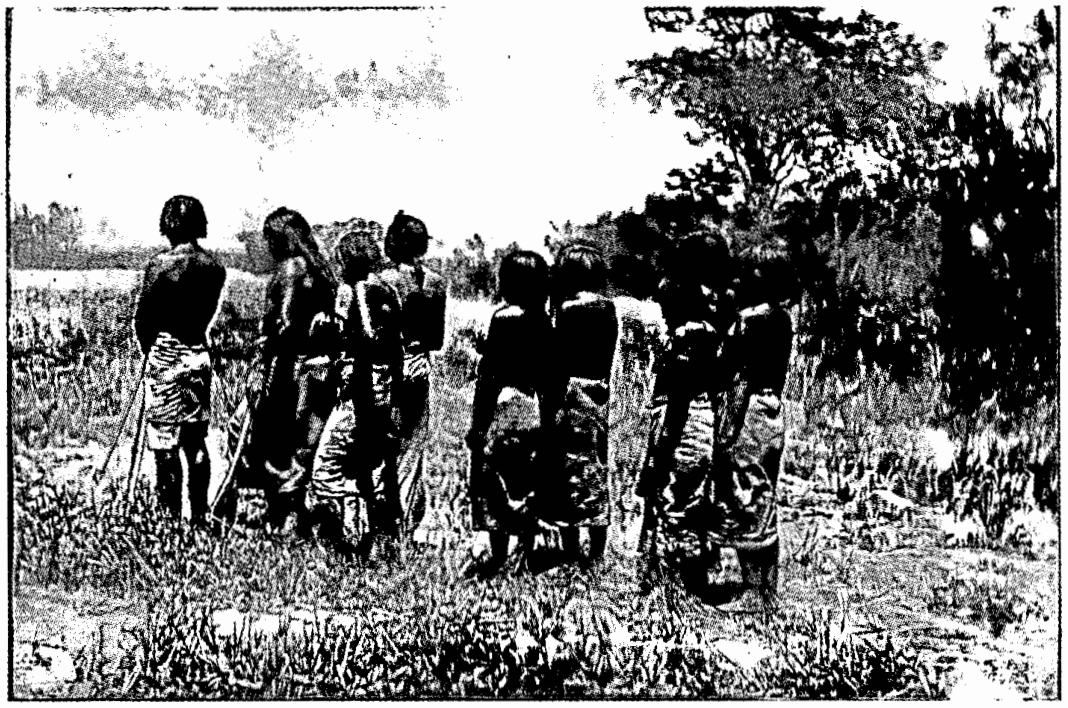

acera del palacio y llegar finalmente a la catedral.

La procesión era encabezada por una escuadra de caballería, destacamentos de artillería con seis cañones, cuatro caballos enlutados en cuyos mantillones lucían las armas de la familia del difunto. El sargento mayor de la plaza y sus ayudantes a caballo eran seguidos por las compañías de granaderos, los pobres del hospicio portando cirios encendidos, todas las cofradias, comunidades religiosas, santas escuelas, cruces parroquiales y cabildo metropolitano. A continuación iba la urna custodiada por alumnos del colegio militar y sosteniendo las seis "borlas" del ataúd marchaban militares, ministros, un miembro del ayuntamiento y otro de la universidad. Detrás de ella iba el comandante general con su estado mayor, miembros de la universidad, los colegios, el ayuntamiento y otras autoridades como el consejo de gobierno.

La procesión fúnebre era presidida por una comisión integrada por miembros de los tres poderes. Juan Gómez Navarrete, albacea del héroe de Iguala, tenía un destacado lugar junto con el presidente de la Cámara de Diputados, Alfonso Fernández, quien fungía en este acto como el doliente principal. ${ }^{51}$ Joaquín Iturbide, único pariente del

51 Resumen sacado de El Iris, 24 octubre 1838; Pacheco, Descripción, 1849, pp. 79-84; Bustamante, "Diario", 26 octubre 1838; El Cosmopolita, 27 octubre 1838. 
difunto, que participó en el cortejo, mandó publicar en la prensa el agradecimiento que - a nombre de la familiahacía al presidente de la comisión del ceremonial por las diligencias seguidas para que esa "lúgubre función tuviese toda la solemnidad y magnificencia debida".52

En otra litografia de Cumplido se aprecia la valla formada por el ejército, en cuyo centro marcha el cortejo en perfecto orden, con los caballeros y caballos dignamente engalanados y el carro luctuosamente adornado. La urna se advierte colocada a una altura donde puede ser apreciada por la multitud. Igualmente se nota que las banderas del Palacio Nacional y de la catedral están a media asta y ondean en medio del humo de los cañones que disparan sus salvas. Era una ceremonia que los fervientes admiradores de Iturbide hubieran deseado que se efectuara en el momento de la muerte y no varios años después.

A las dos de la tarde, cuando terminó de llegar toda la processión a la cate. dral, la urna ya había sido debidamente colocada en otro suntuoso catafalco. Al decir de Bustamante, la pira se había utilizado algunos años atrás en las honras del arzobispo Francisco Xavier Lizana. ${ }^{53}$ Más tarde, se celebraron vísperas y Braulio Sagaceta pronunció una oración fúnebre en latín, cuyo contenido se desconoce pero no es difícil adivinar. Acto seguido, regresó la

52 El Irts, 14 noviembre 1838.

53 Bustamante, "Diario", 27 octubre 1838. La costumbre de "reciclar" las piras había tenido gran difusión en Nueva España. comitiva al palacio a dar el pésame al presidente, quien se encontraba en un salón enlutado.

La mañana del célebre día 27 de octubre se celebraron unas exequias con una oración en español pronunciada por José María Castañeda. Terminada ésta, se depositó la urna en la capilla de San Felipe de Jesús. Posteriormente se colocó un epitafio que a la fecha puede leerse y que dice:

\section{Agustin de Iturbide, autor de la independencia mexicana. Compatriota, llóralo; pasajero, admiralo.}

Terminadas las ceremonias religiosas, hubo todavía un acto cívico en la Alameda, cuyo orador fue el catedrático del Colegio de San Juan de Letrán, Manuel Tosiat Ferrer. ${ }^{54}$

\section{REACCIONES}

Las referencias del pesar generalizado que experimentaba la población, recogidas en la descripción de Pacheco, se contraponen a los comentarios de los periódicos que tienen un tono más rea. lista:

Los cañonazos y dobles repetidos han estado anunciando la solemnidad y han debido considerarse como una continua invitación a todos los habitantes de esta ciudad para unir sus sentimientos a los del supremo gobierno, que se muestra inconsolable y profundamente pesa-

54 Romero Flores, Iturbide, 1971, p. 64. 
roso a causa del asesinato perpetrado en Padilla en la persona del señor Iturbide. Sin embargo, los habitantes de esta populosa ciudad no se han cuidado de corresponder a esas invitaciones. 55

Las autoridades aparentemente no contaban con el poder de convocatoria necesario para imponer por la fuerza y aun legitimar su nuevo símbolo.

El Cosmopolita criticó además, la gran cantidad de dinero (el presupuesto inicial fue de cerca de 14000 pesos) gastada en una pompa innecesaria y consideró que hubiera estado mejor invertida en partidas más esenciales, como alimentos y sueldos. Por otro lado, resaltaba que el reglamento aprobado por el gobierno

consulta honores que no sabemos por qué ley le convengan al señor don Agustín Iturbide; no murió emperador y la nación abjuró de esegobierno; por consiguiente no le convienen los honores de tal. Tampoco los del presidente de la república, porque nunca obtuvo tal dig. nidad. Se dirá que fue héroe de Iguala y ¿cuáles son los honores decretados para los héroes?56

Por si fuera poco, como bien observó Bustamante, los sonidos salidos de la "campana mayor de catedral [son] lo que llaman impropiamente vacante de un imperio que no está vaco, en un país que quince años ha que está constituido en república". ${ }^{57}$

Acaso el gobierno conservador que-

55 El Cosmopolita, núm. 93, 27 octubre 1838.

56 El Cosmopolita, núm. 92, 25 octubre 1838.

57 Bustamante, "Diario", 25 octubre 1838. ría recordar una etapa que era aborrecida por gran parte de la población aunque fuera de la predilección del grupo en el poder.

El periódico citado recogió el rumor de que se había querido engañar a la multitud "presentando una calavera que no es del señor Iturbide; en efecto, la que ha salido en lúgubre triunfo es de cera fabricada en esta capital". ${ }^{58} \mathrm{La}$ cabeza había sido víctima de las balas que la habian desintegrado en múltiples pedazos. Pacheco confiesa que deseaba sacarle un moide pero que la operación no se pudo concretar porque se habían perdido algunas piezas. El mismo conservó una de las partes y elaboró toda una teoría sobre las virtudes del héroe con base en la forma del cráneo. ${ }^{59}$ Por su parte, Bustamante comentó haber sostenido "la calavera que es enorme", aunque los huesos no estaban completos y vio que se les limpiaba y barnizaba con cloruro. "No sé cómo los han de armar y cubrir de cera." 60 Un símbolo tan importante para la veneración del héroe había tenido que ser prácticamente inventado.

El mismo autor observó con cierta objetividad que si el presidente Bustamante quería honrar la memoria de su bienhechor, conservara

esas afecciones de modo que no turben la paz pública que debe conservar como el primero de sus deberes. ¿Por qué no le erigió a sus expensas un sepulcro de. cente en Padilla y dejó que la lima del tiempo gastase lo que pudiera hacer odiosa la memoria de este personaje,

58 El Cosmopolita, 27 octubre 1838.

59 Pacheco, Descripctón, 1849, p. 74.

60 Bustamante, "Diario", 22 octubre 1838. 
reservando a la generación futura estos honores cuando su mérito se vería en tercer término y ya no hubiera pasiones exaltadas como las que hoy existen por sus contemporáneos? ${ }^{61}$

El capricho de A nastasio Bustamante de estar cerca de su amigo quedó demostrado cuando, al elaborar su testamento, pidió que a su muerte se extrajera su corazón y se depositara junto con los restos de Iturbide, voluntad que fue cumplida por sus albaceas el 28 de septiembre de $1853 .{ }^{62}$

No quiero atribuir el rescate de Iturbide a la voluntad del presidente Bustamante ni al último deseo de Mier y Terán, sino que veo tras él las acciones de una facción conservadora que busca. ba concretar sus ideales en un símbolo susceptible de veneración. Con esto queda demostrado, una vez más, la observación de David Kertzer en el sentido de que "los nuevos sistemas políticos toman prestada la legitimidad de los antiguos, alimentándose de las viejas formas rituales pero dirigiéndolas a sus nuevos propósitos". ${ }^{63}$

\section{Y LA HISTORI A CONTINÚA}

Los intentos por hacer que persistiera el culto a Iturbide de entonces a la fecha han sido muy diversos y casi siem. pre traídos y llevados por la facción perdedora, pero no por ello carente de recursos para hacer sentir su presen. cia. Los siguientes son sólo algunos de

61 Ibid., 26 octubre 1838.

62 Nota de José Bravo Ugarte a Pacheco, Iturbide, 1964, pp. 91-93.

63 Kertzer, Ritual, 1988, p. 42. los ejemplos que ha sido posible documentar.

En primer lugar, A lamän nos refiere en su Historia de Méjico que las misas por el eterno descanso de Iturbide seguían diciéndose a expensas de la nación hasta que el Congreso, en tiempos del presidente Mariano Arista (1850-51) mandó se celebrasen a expensas del clero. ${ }^{64}$ Seguramente el gobierno liberal consideró que, después de tantos años, ya había pagado su deuda con el héroe de Iguala y, además, limpiado su culpa.

Los vaivenes políticos típicos del siglo XIX colocaron nuevamente en el poder a Santa Anna y, en 1853, el presidente firmó otro decreto más para tratar de oficializar el culto a Iturbide declarándolo "Libertador de la Patria" y ordenando que se colocara su retrato en todas las oficinas públicas. Además restableció la Orden de Guadalupe, fundada por el emperador y a la que él mismo había pertenecido. ${ }^{65}$

Cada año, el 28 de septiembre se celebraban los "sufragios por las víctimas de la patria". En esa ocasión, se abría la capillla de San Felipe de Jesús en la catedral y se prendían algunas hachas de cera para que ardieran junto al sepulcro de Iturbide. Sin embargo, en 1854 El Siglo $X I X$ publicó la queja de que, al llegar los oficiales del batallón de Celaya a rendir honores a su antiguo coronel, encontraron la puerta cerrada. ${ }^{66}$

Además, cada vez que se celebraba la consumación de la independencia el

64 A lamán, Historia, 1985, vol. v, p. 804. 65 Romero Flores, Iturbide, 1971, p. 65. 66 El Siglo XIX, 29 septiembre 1854. 
27 de septiembre, se hacía alguna alusión a Iturbide. Así por ejemplo, en el acto de 1850 Manuel Ramírez de Arellano recalcó que "la tumba no devuelve jamás la presa que se traga, pero los que se hunden en ella como Iturbide, mueren sólo para sus contemporáneos y viven siempre para la posteridad ${ }^{n}{ }^{67}$

Cuando se restableció en México el régimen imperial, Maximiliano de Habsburgo participó, lógicamente, en el intento de rescatar para la historia a su antecesor en el trono. Así pues, el 9 de septiembre de 1865 , firmó un convenio con su familia para la concesión de títulos, posiciones y pensiones. Esto fue interpretado como una maniobra para, ante la falta de sucesión de los Habsburgo, heredarle la corona a un nieto de Agustín I. ${ }^{68}$

Años más tarde, en 1883, durante la administración de Manuel González, surgió la iniciativa de conmemorar el centenario del natalicio de Iturbide. Esta propuesta fue, una vez más, polemizada en la prensa y los festejos encontraron poco eco entre la población. ${ }^{69}$

El primero de enero de 1990 se constituyó - por fin- una "Sociedad Patriótica Agustín de Iturbide". En su reglamento aclaró que había sido fundada "por un grupo de amigos fieles al caudillo de Iguala, amigos de ultratumba, sin interés ni ambiciones bastardas, pues de quien ya no existe, ¿qué recompensa debe esperarse?"70 Ellos se habían ocupado de mandar decir las misas una vez que Pío Marcha y la nue.

67 Ramírez Arellano, Oracion, 1859, p. 24.

68 García, Tortuosa, pp. 147.148.

69 lbid., p. 149.

70 Sociedad Patriótica, Reglamento, 1900, p. 4. ra de Iturbide, Alicia Green, habían desaparecido. ${ }^{71}$ Su objetivo era "la reivindicación de la personalidad del libertador por medio del convencimiento y de la verdad histórica y la manifestación pública de esa misma verdad y de ese mismo convencimiento en los aniversarios" de la consumación de la independencia y la muerte del héroe. El presidente de la Sociedad era el general Manuel Diez de la Vega y el prosecretario Roberto Gayosso. Existian además comisiones encargadas de reunir todo tipo de escritos sobre Iturbide, difundir su "buena opinión", atraer miembros, arbitrar recursos y organizar las celebraciones religiosas y "profanas", etcétera.

Por su parte, el estado de Tamaulipas, por iniciativa de su gobernador Guadalupe Mainero, decidió en 1901 erigir un "modesto" monumento en Padilla, el sitio donde Iturbide había visto la luz por última vez. La intención era, por un lado, conmemorar en un pueblo olvidado un suceso histórico importante y por el otro reivindicar a Tamaulipas, a cuyo Congreso de 1824 se había criticado duramente por decretar el fusilamiento de Iturbide. Se había propuesto originalmente rematar una pirámide truncada con "el águila nacional rompiendo con su garra posada sobre el monumento la corona y el cetro, y con la otra al aire, la espada emblemática de la guerra civil". ${ }^{72}$ Pero este simbólico remate no

${ }^{71}$ Marcha había sido uno de los promotores de la elevación al trono de Agustín I y muchos años después seguía encomendando a Dios el alma del hombre que por ese acto había perdido la vida.

72 Monumento, 1901, p. 118. 
llegó a colocarse ya que, por la muerte del gobernador, el monumento quedó inconcluso. Y nadie lo continuó, al menos hasta 1963, en que lo visitó José Bravo Ugarte. ${ }^{73}$

La tradición resurgió de alguna manera en la segunda década del siglo $x X$ cuando, en 1921, "para conmemorar el centenario de la consumación de la independencia, se decreta quitar el nombre de Iturbide del salón de sesiones del Congreso y arrojar las letras lejos, apagadas las luces". ${ }^{74}$

La iniciativa fue presentada el 22 de septiembre ante la Cámara de Diputa. dos. Jesús Romero Flores ha publicado la transcripción de las sesiones que se dedicaron a considerar la propuesta y en ellas se hace evidente que los ánimos seguían bastante caldeados y que las pasiones no habían quedado atrás. Fuertes acusaciones y mesuradas defensas salpican la discusión, en la que sale a relucir, una vez más, la opinión generalizada de que Iturbide era instrumento servil del clero, verbalizada en las palabras de Vito Alessio Robles:

Una de las principales razones por las que algunos de los compañeros quieren que se borre el nombre de Iturbide es porque el grupo católico de una manera torpe ha querido tomar a Iturbide como bandera, como estandarte, como sím. bolo. 75

Concretamente se le vinculaba con los Caballeros de Colón, a quienes algunos sectores acusaban de querer

\footnotetext{
73 Bravo Ugarte, Documentos, 1964.

74 Gutiérrez, Papeles, 1977, p. 25.

75 Romero Flores, Iturbide, 1971, passim.
}

"inficionar el cerebro de la juventud mexicana".

Todos estos movimientos, hasta llegar a la colocación del óleo en 1992, y los que seguramente se seguirán haciendo, dan una idea bastante clara de que si algo tiene la facción que busca un lugar en la historia, es constancia. $Y$ con ello han logrado, de una u otra manera, llamar la atención sobre la historia de Iturbide.

\section{CONSIDERACIONES FINALES}

Con este ensayo no he pretendido lim: piar la imagen de traidor de Iturbide; sólo he querido destacar que la muerte de un personaje tiene raíces y repercusiones que se usan como símbolos políticos. Además, he intentado favorecer la idea de que la historia no debe ser unilineal, por el contrario, debe tener un enfoque múltiple.

Tradicionalmente, la historia de "bronce", como diría Luis González, destaca a los triunfadores, niega a los perdedores y margina al resto de los sujetos sociales. Quienes han sido receptores de estas enseñanzas sólo con el tiempo, la lectura y la reflexión pueden desprenderse de esa fijación y percatarse de que para tener un conocimiento cabal de los procesos se requiere tomar en cuenta a todos los actores que participan en ellos.

Para el caso que presento, ha sido necesario calibrar las implicaciones de la muerte de Iturbide a corto y largo plazos. Si bien es cierto, como señala Josefina Vázquez, que la noticia de su fusilamiento sirvió para convencer al ministro inglés Canning, de la firmeza 
de las instituciones republicanas, $y$ por tanto de la factibilidad de reconocer la independencia mexicana, ${ }^{76}$ éste fue un logro inmediato. Pero la imagen de Iturbide se mantuvo viva en el siglo XIX y sirvió para que los liberales elaboraran sobre sus cenizas el nuevo discurso político contra las facciones perdedoras, monárquicas y conservadoras.

La lucha contra los representantes de la oposición ha llevado incluso a negar su existencia. La mentalidad política del siglo XIX condenó a Iturbide al olvido, pero más significativo es el hecho de que los legisladores surgidos de la revolución mexicana lo intentaran matar nuevamente con esa ceremonia que he referido, de arrojar a la oscuridad las letras de su nombre.

Por último, se demuestra que la veneración de los símbolos históricos no es eterna. Los grupos en el poder quieren fundamentar su existencia con otras bases y símbolos políticos y el hueco dejado se cubre con la invención de nuevas tradiciones. Pero ésa es otra historia y debe ser contada en otro lado.

\section{BIBLIOGR A FÍA}

-El Águila Mexicana, vol. ıv, año 2, del 15 de abril al 14 de octubre de 1824 .

-Alamán, Lucas, Historia de Méjico desde los primeros movimientos que prepararon su Independencia en el año de 1808 hasta la época presente, Instituto Cultural Helénico/Fondo de Cultura Económica, México, 1985, 5 vols.

-Anna, Timothy E., El imperio de Iturbide, Consejo Nacional para la Cultura y las

76 Vázquez, "República”, 1974, p. 37.
Artes/Alianza Editorial, México, 1991 (Los Noventa, 70).

-Argandar, Francisco, Elogio fúnebre de los primeros héroes y víctimas de la patria, que el 17 de septiembre de 1823, en la Iglesia Metropolitana de México a presencia de una Diputación del Sobera. no Congreso, del Supremo Poder Ejecutivo y demás corporaciones y oficialidad, dijo el Dr...., Imprenta del Supremo Gobierno, México, 1823.

-Beneski, Carlos de, Una narración de los últimos momentos de la vida de don Agustín de Iturbide, ex emperador de Mé. xico, Instituto de Investigaciones Históricas de la Universidad Autónoma de Tamaulipas, Ciudad Victoria, 1977.

-Bocanegra, José María, Memorias para la historia del México independiente 1822-1846, Instituto Nacional de Estudios Históricos de la Revolución Mexicana, México, 1985, 2 vols.

-Bravo Ugarte, José (prólogo y notas), Iturbide. Documentos y folletos selectos sobre su muerte, exhumación y reinhumación y monumento en Padilla, Editorial Jus, México, 1964 (México Heroico, 30).

-Bustamante, Carlos María de, "Diario Histórico de Bustamante". Ejemplar mecanografiado consultado en la Academia Mexicana de la Historia, 1838. , Diario Histórico de México, notas de Manuel Calvillo, edición de Rina Ortiz, Instituto Nacional de Antropología e Historia, México, 1981 (vol. II correspondiente a enero-diciembre de 1824).

-Carlyle, Thomas, Los héroes. El culto de los héroes y lo heroico en la historia, Editorial Porrúa, México, 1976 (Sepan Cuantos, 307).

- Catástrofe de don Agustín de Iturbide, aclamado emperador de México el 18 de mayo del año de 1822 o relación exacta de las circunstancias que han acompañado el desembarco y la muerte de este hombre célebre, reimpreso en la oficina de la Testamentaría de Ontiveros, México, 1826.

-Díaz Noriega, José María, Funestos re- 
cuerdos del libertador de México. Exhumacion y autenticidad de sus respetables restos, conducidos desde Padillay.depositados actualmente en la Santa Iglesia Ca. tedral que al señor coronel don José Ramón Malo dedica el general..., Imprenta de J. M. Lara, México, 1860.

- Entrada de las cenizas de nuestro libertador Iturbide, Hipólito Lagarza, México, 1838.

-Fernández de Lizardi, José Joaquín (El Pensador Mexicano), Pésame del Pensador por la muerte de Iturbide, a sus apasionados, Imprenta de don Mariano Ontiveros, México, 1824. , En donde murió Iturbide viven en paz los traidores, Imprenta de la Testamentaría de Ontiveros, México, 1826.

- García V., Rubén, La tortuosa vida de Iturbide, s.p.i.

-Gutiérrez Casillas, José (S.J.), Papeles de don Agustín de Iturbide, documentos hallados recientemente, Editorial Tradi. ción, México, 1977 (Episodios Nacionales, 10).

-Hobsbawm, Eric y Terence Ranger (comps.), The invention of tradition, Cambridge University Press, Cambridge, 1983 (Past and Present Publications).

-Iturbide, Agustín de, Breve diseño critico de la emancipación y libertad de la nación mexicana y de las causas que influyeron en sus más ruidosos sucesos, acaecidos desde el grito de Iguala hasta la espantosa muerte del libertador en la villa de Padilla, Imprenta de la Testamentaría de Ontiveros, México, 1827.

-J.C.M., Del grande Iturbide se puede decir que vino a reinar después de morir, Impreso por Ignacio Ávila, México, 1838.

-J.M.G., Muerte y entierro de Agustín Primero, Imprenta Liberal a cargo de don Juan Cabrera, México, 1823.

-Kertzer, David I., Ritual, politics and power, Yale University Press, New Haven, 1988.

-Malo, José Ramón, Apuntes históricos sobre el destierro, vuelta al territorio mexicano y muerte del libertador don Agustín de Iturbide, Imprenta de Revista Universal, México, 1869.

-Manda nuestro emperador que ninguno le obedezca, Imprenta Nacional, Puebla, 1823.

-Miguel i Vergés, José María, Diccionario de insurgentes, Editorial Porrúa, México, 1980.

-Monumento de Padilla (18241901). Documentos y antecedentes que lo justifican y determinan los fines de su erección, Oficina Tipográfica del Gobierno, Victoria, 1901.

-Moreno Valle, Lucina, Catálogo de la Colección Lafragua de la Biblioteca Nacional de México 1821-1853, Universidad Nacional Autónoma de México/Instituto de Investigaciones Bibliográficas, México, 1975 (Serie Guías, 2).

-Navarro y Rodrigo, Carlos, Vida de Agustín de Iturbide. Memorias de Agustín de Iturbide, A. Pola, México, 1906.

- Pacheco, José Ramón, Descripción de la solemnidad fúnebre con que se honra. ron las cenizas del héroe de Iguala, don Agustín de Iturbide, en octubre de 1838, Imprenta de Ignacio Cumplido, Mćxico, 1849.

-Payno, Manuel, Bosquejo biográfico de los generales Iturbide y Terán, Impreso por Ignacio Cumplido, México, 1843.

-R.S.H. y C., A Iturbide y Guerrero recordamos sus nombres y cadáveres deseamos, Imprenta a cargo del C. José Uribe y Alcalde, México, 1831.

-Ramírez de Arellano, Manuel, Oración cívica pronunciada en la Alameda de México el día 27 de septiembre de 1859, Imprenta de J. M. Lara, México, 1859.

-Robertson, William Spence, Iturbide of Mexico, Duke University Press, Durham, 1952.

-Romero Flores, Jesús, Iturbide, pro y contra, Balsal Editores, Morelia, 1971 (Documentos y Testimonios, 4).

-Segunda parte o conclusión del testa- 
mento de Iturbide, reimpreso en La Liberal, Puebla, 1832.

-Sociedad Patriótica Agustín de Iturbide, Reglamento, Compañía Industrial Ascorve y Gayosso, México, 1900.

-Tulard, Jean, "Le retour des cendres", en Pierre Nora (dir), Les lieux de memoire, II La Nation, Gallimard, Paris, 1986, pp. 81-110 (Bibliothèque Illustrée des Historiens).

-Valle, Rafael Heliodoro, Iturbide, varón de Dios, Ediciones Xóchitl, México, 1944 (Vidas Mexicanas, 12).

-Vázquez, Josefina $Z$., "La república federal", en Historia de México, Salvat Editores, México, 1974, vol. viI, pp. 33-46.
-Villavicencio, Pablo de [El Payo del Rosario], El Payo del Rosario a la grata memoria de Iturbide, Oficina de la Testamentaría de Ontiveros, México, 1826. Nos va dando cierto olor a segundo emperador. O sea la Logia de los gatos número 2, Imprenta del Ciudadano Mariano Malagón, México, 1831.

-Zavala, Lorenzo de, Ensayo histórico de las revoluciones de México desde 1808 hasta 1830, Instituto Cultural Helénico/Fondo de Cultura Económica, México, 1985.

-Zorrilla, Juan Fidel, Los últimos días de Iturbide, Librería de Manuel Porrúa, México, 1969 (Biblioteca Mexicana, 40). 


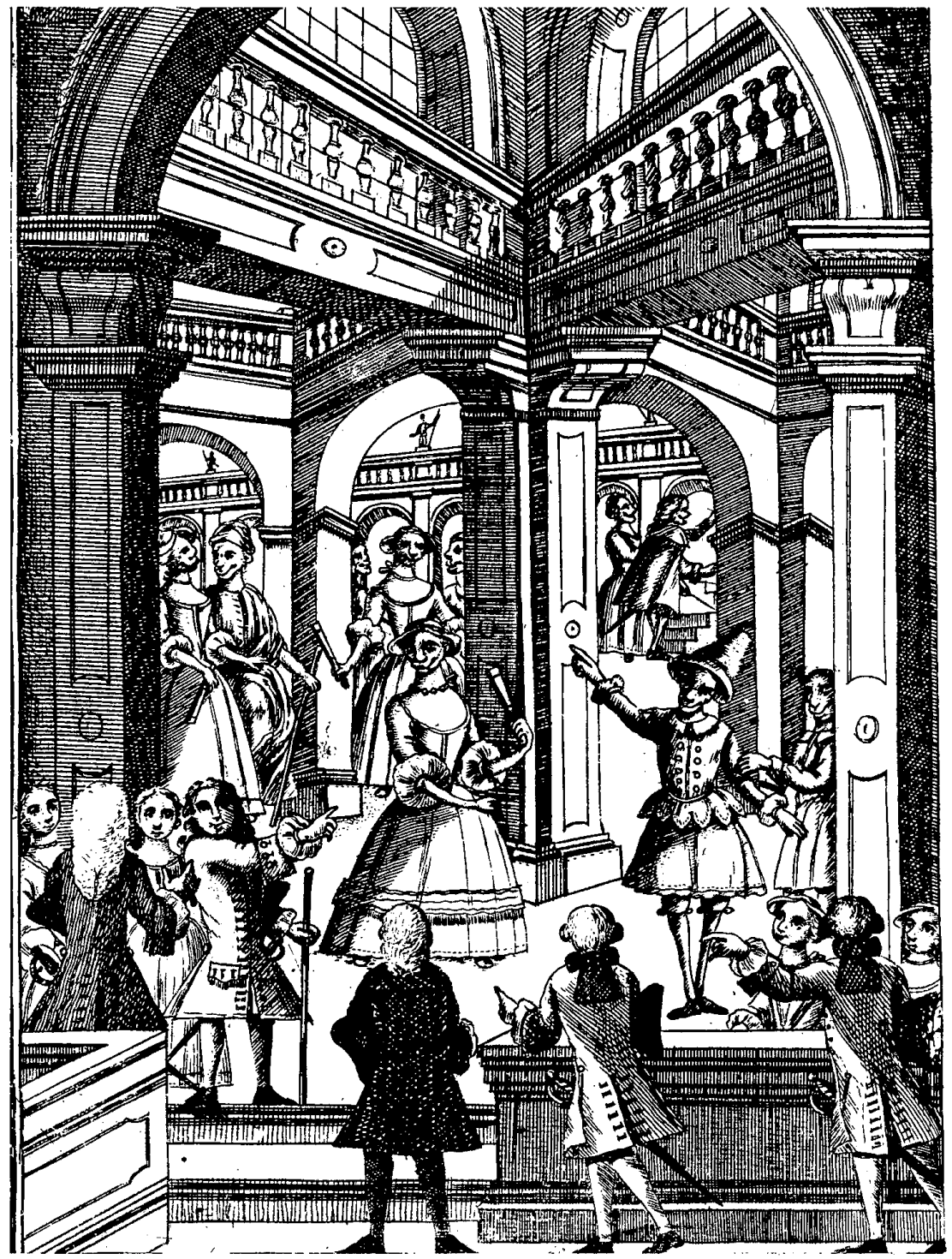

